\title{
Three-dimensional pore structure of activated carbon monolithic derived from hierarchically bamboo stem for supercapacitor application
}

\author{
Erman Taer ${ }^{a^{*}}$, Lini Pratiwi ${ }^{a}$, Apriwandia ${ }^{a}$ Widya Sinta Mustika ${ }^{a}$, Rika Taslim ${ }^{b}$, Agustino $^{\text {a }}$ \\ ${ }^{a}$ Department of Physics, University of Riau, 28293 Simpang Baru, Riau, Indonesia \\ ${ }^{b}$ Department of Industrial Engineering, State Islamic University of Sultan Syarif Kasim, 28293 Simpang Baru, Riau, Indonesia
}

Article history:

Received: 20 May 2020 / Received in revised form: 29 May 2020 / Accepted: 31 May 2020

\begin{abstract}
A three-dimensional pore structure on activated carbon derived from hierarchically bamboo stem was synthesized in the monolithic form for increased applicability as a supercapacitor electrode. The preparation involved two step carbonizations, using a chemical activation at different concentrations. Subsequently, the morphology, chemical content, specific surface area and pore size distribution, as well as crystalline degree were evaluated with scanning electron microscopy, energy X-ray (EDX), $\mathrm{N}_{2}$ sorption and X-ray diffraction, respectively. Therefore, cyclic voltammetry $(\mathrm{CV})$ was used to assess the electrochemical performance, in a two electrode system. The result shows the significant impact of the three-dimensional structure on electrochemical performance, and the optimized sample exhibited specific capacitance of $168.8 \mathrm{~F} \mathrm{~g}^{-1}$, energy density of $23.44 \mathrm{Wh} \mathrm{kg}^{-1}$, and power density of $84.46 \mathrm{~W} \mathrm{~kg}^{-1}$.
\end{abstract}

Keywords: Activated carbon, bamboo stem, monolitich, three-dimensional structure, supercapacitor

\section{Introduction}

Supercapacitors are attractive energy strategies for reducing environmental pollution from fossil fuel exploitation. This technology is characterized by high energy/power, high charge/discharge rate, and long cycle life [1], and are generally classified into two energy storage mechanism, including (1) pseudo-capacitance with faradic redox. (2) Electrochemical double layer capacitance (EDLC) devoid of faradic redox [2], also defined as an accumulation of ion pairs, compromising the electrostatic interaction with polarized electrodes [3]. This mechanism is affected by the electrode architecture and porous texture, hence the materials selected for use are of high importance [4]. There is rising interest in the use of carbon-based materials, including carbon aerogel [5], foam [6], fiber [7], nanotube [8], and graphite [9]. Particularly, activated carbon is suggested as an attractive resource, due to the sustainability, easy production and cost effectiveness [10].

Furthermore, precursor selection is a crucial process because the carbon sources influences the textural and structural characteristic as well as yield of the final product $[11,12]$. In addition, lignocellulosic biomass are the most commonly used activated carbon resources, due to the abundant availability, eco-friendliness, and processing versatility [13]. The major chemical composition include cellulose, hemicellulose and lignin, linked by $\mathrm{C}-\mathrm{O}-\mathrm{C}$ or $\mathrm{C}-\mathrm{C}$ bonds [14]. Moreover, the average elemental constituent in hemicellulose include carbon (44.4 wt\%), oxygen (49.4 wt\%)

\footnotetext{
* Corresponding author.
}

Email: erman.taer@lecturer.unri.ac.id and hydrogen (6.2 wt\%). This composition is relatively similar to cellulose, while lignin consists of carbon (62 wt\%) and oxygen (32 wt\%) [15]. Furthermore, the biomass typically includes wood as a major component and grass [16].

For example, bamboo is a lignocellulosic-based material, comprising about $43.44 \%$ cellulose, $29.56 \%$ hemicellulose, and $27.52 \%$ lignin [17]. This contains a natural porous network, known to support the generation of threedimensional (3D) pore structures [18], and also provide high ion transport [16]. Therefore, bamboo has been suggested as a supercapacitor electrode, and some reports show the fabrication into powder forms, under varied conditions, including temperature of carbonization [19] and activation $[18,20]$, chemical treatment with $\mathrm{KOH}[18,21,22]$ or molten carbonate [23], as well as doping with heteroatom (S, N, B) [22,24,25]. Unfortunately, the phenomenon of dusting reduces mechanical strength, while binder materials lead to poor electrical conductivity and high production cost [2]. Therefore, free standing electrodes devoid of binder materials are necessary for further supercapacitor application.

The focus of previous studies has been limited to enhancing electrochemical performance, and there are only a few literatures discussing the application of activated carbon without binder as supercapacitor electrode. Some reports on binder-free electrodes consist of mixtures with a nanocomposite $\mathrm{MnO}_{2}$ [26,27], leading to poor production cost effectiveness and electrical conductivity. Meanwhile, the monolith forms are recommended for the low cost and ease of processing binder free electrode, subsequently ensuring good mechanical strength and high electrical conductivity [2].

Therefore, in this study, we report on the synthesis of 
activated carbon from hierarchically bamboo stem in the monolithic form, to be used as binder free electrode for supercapacitor application. The raw material was first treated in two step carbonizations, followed by chemical activation using different concentrations ( $1 \mathrm{M}$ and $3 \mathrm{M}$ ) of potassium hydroxide $(\mathrm{KOH})$. Then, structure characterization to activated carbon monolithic were done using a scanning electron microscopy (SEM), $\mathrm{N}_{2}$ gas sorption, $\mathrm{X}$-ray diffraction (XRD), and energy X-ray (EDX). Furthermore, the electrochemical performance was then tested, using cyclic voltammetry $(\mathrm{CV})$ in $1 \mathrm{M} \mathrm{H}_{2} \mathrm{SO}_{4}$ electrolyte, assembled in two electrode system. The effect of chemical activation of activated carbon monolithic on their density will also be discussed in detail. The effect of electrode thickness on their electrochemical performance also will be discussed in this study.

\section{Materials and Methods}

\subsection{Monolithic Electrode Preparation}

Green bamboo stem was collected in Riau province, Indonesia, and prepared into pellet formed with a diameter of around $3 \mathrm{~cm}$, by cross sectional cutting. These were then dried in the oven at temperature at $110{ }^{\circ} \mathrm{C}$ for 48 hours, and activated through two-step carbonization, under a $\mathrm{N}_{2}$ environment, as illustrated in Fig. 1. The first step involves the carbonization process, conducted through a multi-step heating temperature (Fig. 1(a)). This process was initiated at $30{ }^{\circ} \mathrm{C}$ (room temperature) and raised up to $339^{\circ} \mathrm{C}$, at a low heating rate of $1{ }^{\circ} \mathrm{C} / \mathrm{min}$, held for 1 hour. The material was then decomposed to produce higher carbon content.
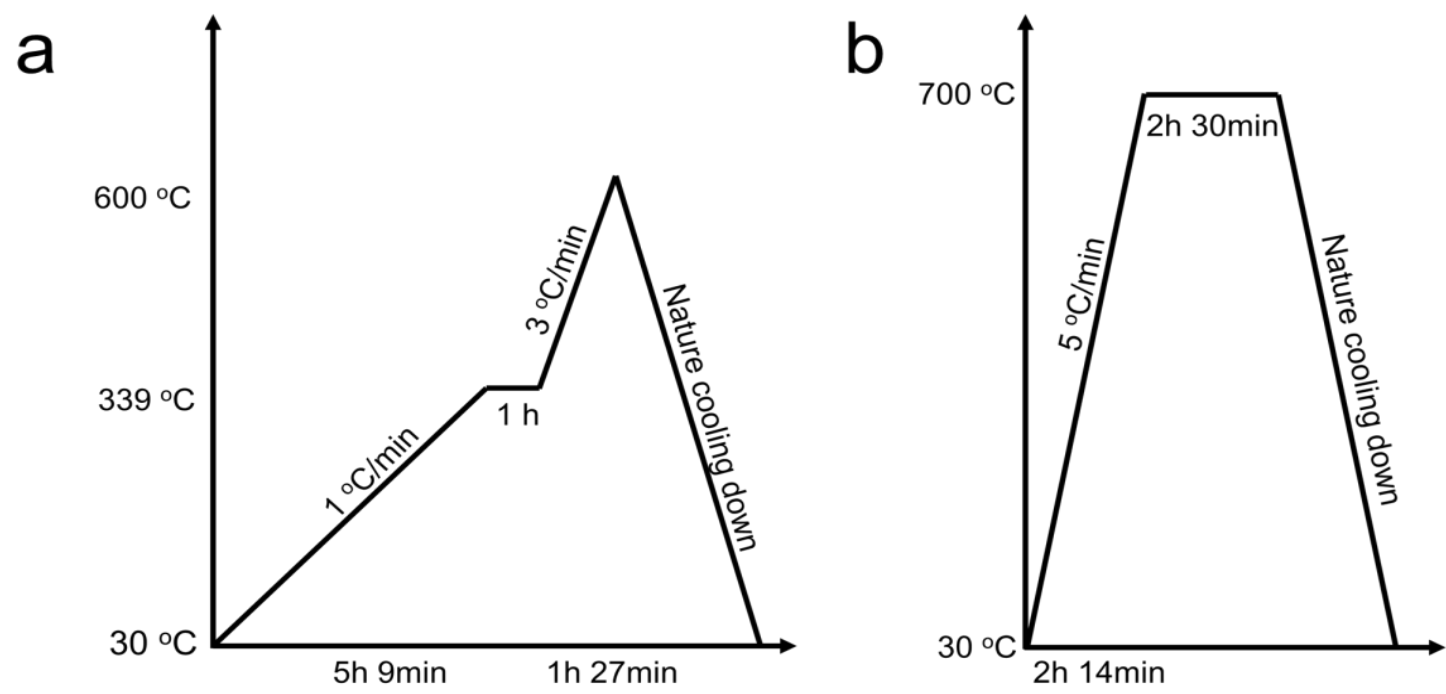

Fig. 1. Carbonization profile:; (a) first step carbonization; (b) second step carbonization.

Therefore, carbonization was continued to maximum temperature of $600{ }^{\circ} \mathrm{C}$, featuring the reduction of some low molecular weight volatile components. The entire process was terminated by cooling naturally to room temperatures, hence the hierarchically bamboo carbon (HBC) is produced without binder.

Subsequently, the HBC samples were polished into a diameter of $0.8 \mathrm{~cm}$, followed by chemical activation by immersing into potassium hydroxide $(\mathrm{KOH})$ solution served at different concentration of $1 \mathrm{M}$ and $3 \mathrm{M}$. Therefore, the hierarchically bamboo porous (HBP) based activated carbon monolith was produced and the samples were labeled HBP-s, where s denotes the specific $\mathrm{KOH}$ concentration. Figure 1(b) shows the carbonized profile for the second phase, which involved single-step heating at a high rate of $5{ }^{\circ} \mathrm{C} / \mathrm{min}$. This carbonization was initiated at $30{ }^{\circ} \mathrm{C}$ up to $700{ }^{\circ} \mathrm{C}$, followed by soaking for 2.5 hours. Therefore, new pores were generated, and finally the activated carbon HBP-s was polished and washed with deionized to achieve neutral $\mathrm{pH}$. However, the samples were polished with two varied thickness, of 0.3 and $0.2 \mathrm{~mm}$, denoted HBP-sa and HBP-sb, respectively for electrode performance evaluation.

\subsection{Structure Characteristic}

The monolithic characteristics were assessed based on the parameters of mass, diameter, and thickness, which were subsequently calculated into density. These values were obtained to evaluate the changes in the first and second step carbonization process, while the morphology and chemical compositions were investigated using scanning electron microscopy (SEM)(JEOL-JSM-6510LA) and energy X-ray (EDX), respectively. In addition, the SEM image was derived at an accelerating voltage of $15 \mathrm{kV}$, with secondary electron image. The Brunauer-Emmett-Teller (BET) and Barret-JoinerHalenda $(\mathrm{BJH})$ methods were applied for observing specific surface area $\left(\mathrm{S}_{\mathrm{BET}}\right)$ and pore size distribution (PSD), respectively. These were measured using $\mathrm{N}_{2}$ gas sorption at temperature of $77.35 \mathrm{~K}$, by employing the Quantachrome Instrument TouchWin Version 1.2.

The crystalline degree of HBP-s samples was observed using the X-ray diffraction (XRD) (Phillip X-Pert Pro PW3060/10), measured with $\mathrm{Cu}-\mathrm{K} \alpha$ radiation $(\mathrm{K} \alpha=1.5418 \AA)$ source in the $2 \theta$ scale range of $10-100^{\circ}$. Furthermore, the XRD parameters, including interlayer spacing $(d)$ and microcrystallites dimension was calculated using the respective equations. 


$$
\begin{aligned}
& n \lambda=2 d \sin \theta \\
& L_{c}=0.89 \lambda / \beta \cos \theta_{002} \\
& L_{a}=1.94 \lambda / \beta \cos \theta_{100}
\end{aligned}
$$

Where, $\mathrm{n}$ denotes the mean diffraction order in value, with 1 as the maximum. $\lambda$ is the $\mathrm{X}$-ray wavelength for $\mathrm{Cu}-\mathrm{K} \alpha$ at radiation of $1.5418 \AA$, while $d$ was defined as the interlayer $d$ spacing, where $d_{002}$ and $d_{100}$ respectively signify $\theta_{002}$ and $\theta_{100}$. In addition, $\theta$ is the angle of reflection plane, at 002 and 100 , respectively, while $L_{c}$ and $L_{a}$ is the mean crystallite dimension in $\AA$ along a line normal to the corresponding reflecting plane. The parameter $\beta$ represents the full width at half-maximum of the plane $2 \theta$, while $\theta$ is the scattering angles (degree).

\subsection{Electrochemical Performance}

Electrochemical performance was tested in a two electrode system, using Cyclic Voltametry (CV) (CV UR Rad-Er 5841, Materials Laboratory, Department of Physics, University of Riau, Indonesia). The supercapacitor cell was assembled in the form of sandwich layers, encompassing the body cell, isolator, current collector, electrode, separator, and liquid electrolyte, while the HBP-s samples served as electrodes, and were immersed in $1 \mathrm{M} \mathrm{H}_{2} \mathrm{SO}_{4}$ electrolyte for 2 days. The two electrodes were placed onto separate circle stainless steel, to serve as the current collector, with thickness of $\approx 0.4 \mathrm{~mm}$, and duck eggshell was applied as a separator [28]. These components were then packaged with teflon and acrylic as isolator and body cell, respectively, and the supercapacitor cell was finally connected to operate and counter the $\mathrm{CV}$ instrument electrode port. In addition, the $\mathrm{CV}$ measurement was performed at a voltage range of 0.0 to 1.0 $\mathrm{V}$, and the data was recorded using Cyclic Voltammetry graphical user interface (CVv6). This apparatus was previously calibrated to VersaStat II Princeton Applied Research, with an error of $\pm 6.05 \%$.

The sample electrochemical properties, including the specific capacitance, energy and power densities were evaluated by calculating the $\mathrm{CV}$ data, using the respective equations.

$$
\begin{aligned}
& C_{s p}=\frac{I_{c}-I_{\text {d }}}{m x s} \\
& E=\frac{1}{2} C_{s p} \Delta V^{2} \times \frac{1000}{3600} \\
& P=\frac{E}{\Delta t / 3600}
\end{aligned}
$$

Where $C_{s p}$ denotes specific capacitance $\left(\mathrm{F} \mathrm{g}^{-1}\right), I_{c}$ and $I_{d}$ respectively signify the charge and discharge current $(\mathrm{A}), m$ served as the average mass loading of two electrodes $(\mathrm{g})$, and $E$ represents the average energy density of the electrode (Wh $\left.\mathrm{kg}^{-1}\right)$. Also, $\Delta V$ and $\Delta t$ respectively designate the potential window of $\mathrm{CV}(\mathrm{V})$ and clearance time in the discharge process (s), while $P$ is the electrode average power density (W $\left.\mathrm{kg}^{-1}\right)$.

\section{Results and Discussion}

\subsection{Mass, Diameter, Thickness, and Density}

The average mass of HBP-s pellet prior to the carbonization process was recorded as 1.174 and $0.912 \mathrm{~g}$ respectively for HBP-1 and HBP-3. Furthermore, a 60-64 \% decline was observed without chemical activation at temperature of $600{ }^{\circ} \mathrm{C}$ (Step-1). These mass losses were attributed to the release of low molecular volatiles, including oxygen, hydrogen and nitrogen during treatment. The pellet diameter also decreased from $\sim 3 \mathrm{~cm}$ to $\sim 1.65 \mathrm{~cm}$ after step-1, resulting from carbon atom rearrangement. Also, the average mass, thickness, diameter and density of all 20 duplicate samples were recorded after treatment at $600{ }^{\circ} \mathrm{C}$ (Step-1) and $700{ }^{\circ} \mathrm{C}$ (Step-2). Table 1 shows the continuous data at similar thickness with varied $\mathrm{KOH}$ concentrations, and the decline in density recorded after step-2 for HBP-1 and HBP-3 was attributed to mass loss and volume shrinkage. The carbonization temperature of $700{ }^{\circ} \mathrm{C}$ also assisted the chemical activation to etch some carbon chains and leave some numerous vacancies [11]. These vacancies instigate carbon atom rearrangement, leading to a decline in pellet diameter. Moreover, density shrinkage also signify pore generation and porosity development, and this ensures better ion diffusion and improved electrochemical performance [29].

Table 1. Average mass, thickness, diameter and density.

\begin{tabular}{lcccc}
\hline \multirow{2}{*}{ Parameters } & \multicolumn{2}{c}{ HBP-1 } & \multicolumn{2}{c}{ HBP-3 } \\
\cline { 2 - 5 } & Step-1 & Step-2 & Step-1 & Step-2 \\
\hline Mass (g) & 0.106 & 0.095 & 0.095 & 0.090 \\
Thickness (cm) & 0.083 & 0.080 & 0.080 & 0.080 \\
Diameter (cm) & 1.663 & 1.651 & 1.585 & 1.513 \\
Density $\left(\mathrm{g} / \mathrm{cm}^{3}\right)$ & 0.605 & 0.554 & 0.599 & 0.564 \\
\hline
\end{tabular}

\subsection{Scanning Electron Microscopy}

Fig. 2 shows the morphology and structure of carbon samples observed through scanning electron microscopy (SEM). This parameter was influenced by the nature of raw materials selected, chemical activating agent used and the other treatment in the production of activated carbon. In addition, treatments in Step-1 cause carbon atom rearrangements, due to the release of low molecular weight volatiles, including oxygen, hydrogen and nitrogen, into the gaseous phase [11]. Subsequently, the chemical activation with $\mathrm{KOH}$ generates new pores during Step-2 carbonization [30].

Fig. 2(a) shows the cube-like three-dimensional hierarchical structure of HBP-1 [18,31], with maximum and minimum size of around 17.28 X $10 \mu \mathrm{m}$ and $20.41 \times 57.70$ $\mu \mathrm{m}$. These materials are covered by some walls, which subsequently contribute to pore blocking. In addition, $\mathrm{KOH}$ activation also results in some new pore formations on the cube surfaces, measuring around $\sim 200 \mathrm{~nm}$. Fig. 2(b) shows the characteristic rough surfaces of HBP-1, as shown by the marked region, indicating the limitations of $1 \mathrm{M} \mathrm{KOH}$ activation to carbon bound etching in bubble forms, and not proper pore development.

Fig. 2(c) showed the HBP structural modification caused by the highly alkaline $3 \mathrm{M} \mathrm{KOH}$. Based on the measurements, hierarchical cubes are larger than HBP-1, with a size range of $21.73 \times 26.02 \mu \mathrm{m}$ and $25.81 \times 76.22 \mu \mathrm{m}$ for the minimum 
and maximum cubes, respectively. The incidence of pore blocking was also reduced by collapsing the covered walls. In addition, HBP-3 exhibits a greater number of new pores formed on the hierarchical cubes surface, with larger size in the macropore range of around $\sim 400 \mathrm{~nm}$, possibly serving as a channel for ion diffusion into the deeper pore [32]. Furthermore, the $3 \mathrm{M} \mathrm{KOH}$ activation also successfully generated new pores, as shown by the marked region of Fig.2 (d), and sample HBP-3 presents with a smooth surface, assumed to provide larger specific surface area compared to HBP-1. Also, HBP-3 achieved a unique flake structure, believed to ensure better electrical conductivity $[33,34]$, and provide better electrochemical performance as predicted.
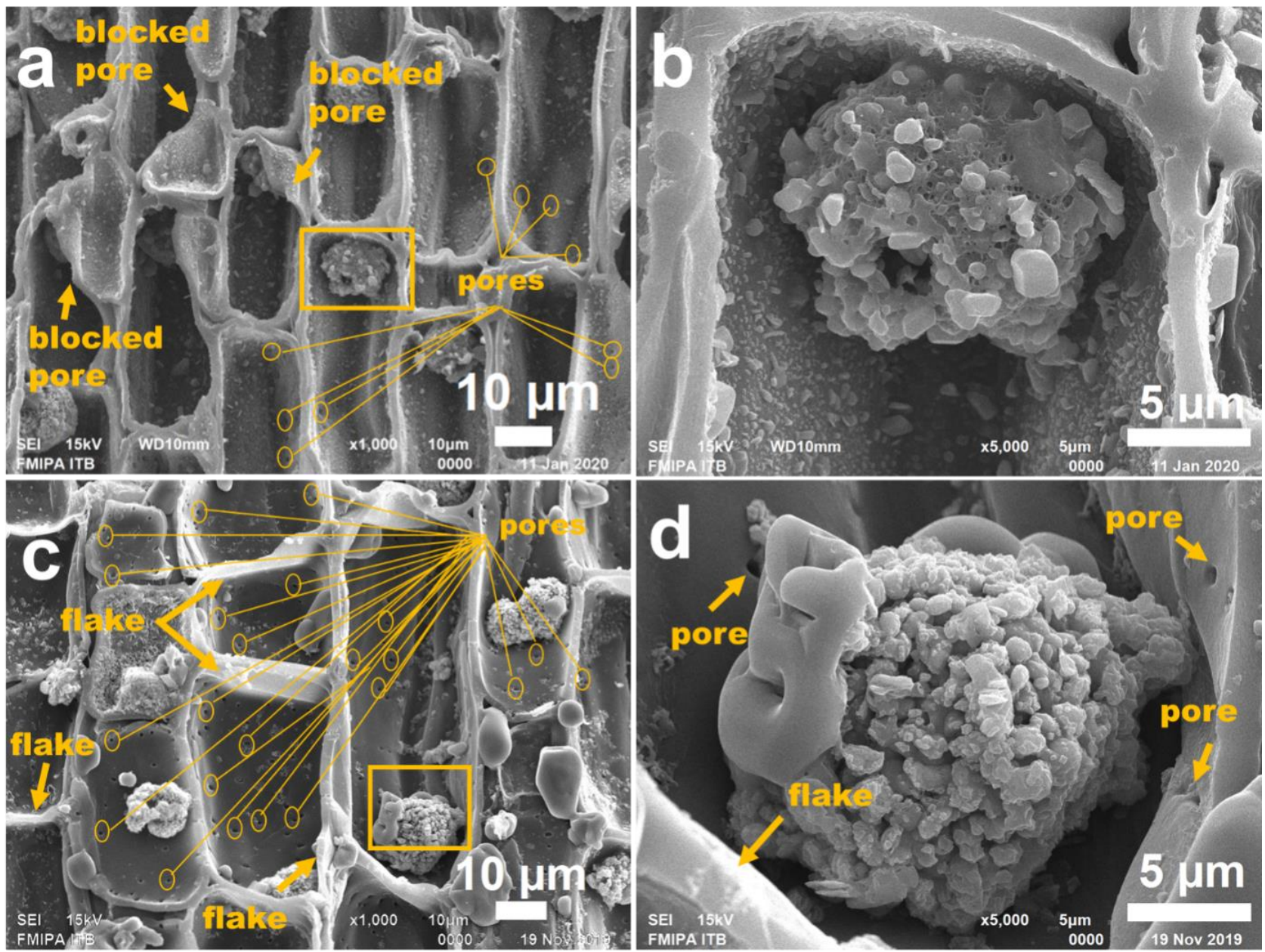

Fig. 2. SEM images of samples: (a) HBP-1; (b) is the enlarged image of the selected region in (a); (c) HBP-3; (d) is the enlarged image of the selected region in (c).

\section{$3.3 \mathrm{~N}_{2}$ Sorptions}

Fig. 3 shows the $\mathrm{N}_{2}$ adsorption/desorption isotherms from HBP-s samples. These were identified according to the international union of pure and applied chemists (IUPAC), as type IV as well as mesopores sorption [32]. Fig. 3(a) depicts the crossed neck of hysteresis at relative pressure $\sim 0.4 \mathrm{P} / \mathrm{P}_{0}$ in HBP-1, associated with the ink bottle pore shape induced pore blocking [35]. Fig. 3(b) shows the isotherm broad knee of hysteresis for HBP-3, affiliated with widening mesopore development [36]. In addition, Equation (6) depicts the chemical activation mechanism of carbon materials with $\mathrm{KOH}$, where $\mathrm{K}$-bound and $\mathrm{K}_{2} \mathrm{CO}_{3}$-occupied are removed by washing. This phenomenon consequently results in the generation of numerous new micropore vacancies [2]. The strong alkaline activation possibly produce larger pores [26], as evidenced by the BHJ methods (not seen here), where higher $\mathrm{KOH}$ concentration led to mesopore formation. These obviously measured $3.27 \mathrm{~nm}$ and $3.57 \mathrm{~nm}$ for HBP-1 and HBP-3, respectively.

$$
6 \mathrm{KOH}+2 \mathrm{C} \rightarrow 2 \mathrm{~K}+3 \mathrm{H}_{2}+2 \mathrm{~K}_{2} \mathrm{CO}_{3}
$$

Table 2 shows a summary of HBP-s sample textural properties, where higher $\mathrm{KOH}$ concentrations significantly increase the specific surface area $\left(\mathrm{S}_{\mathrm{BET}}\right)$ from 2.04 to 154.65 $\mathrm{m}^{2} \mathrm{~g}^{-1}$. However, a decline was observed for mesopores $\left(\mathrm{S}_{\mathrm{MESO}}\right)$, and also in terms of volume $\left(\mathrm{V}_{\mathrm{MESO}}\right)$. These results indicate the ability for $1 \mathrm{M} \mathrm{KOH}$ activation to generate very little amount of micropores in HBP-1, while more are created in treatments with $3 \mathrm{M} \mathrm{KOH}$, leading to the improved specific surface area observed in HBP-3. Furthermore, HBP-1 demonstrated a large average diameter $\left(\mathrm{D}_{\mathrm{AVE}}\right)$ of about $\sim 17$ $\mathrm{nm}$, indicating the possibility that $1 \mathrm{M} \mathrm{KOH}$ activation only opened the hierarchical pore. However, HBP-3 exhibited an average pore diameter of $\sim 2.2 \mathrm{~nm}$, typical to mesopores, and presented in the narrow gap of micropores. This arrangement improves the suitability for ion storage, and the consequent increase in electrochemical performance. 

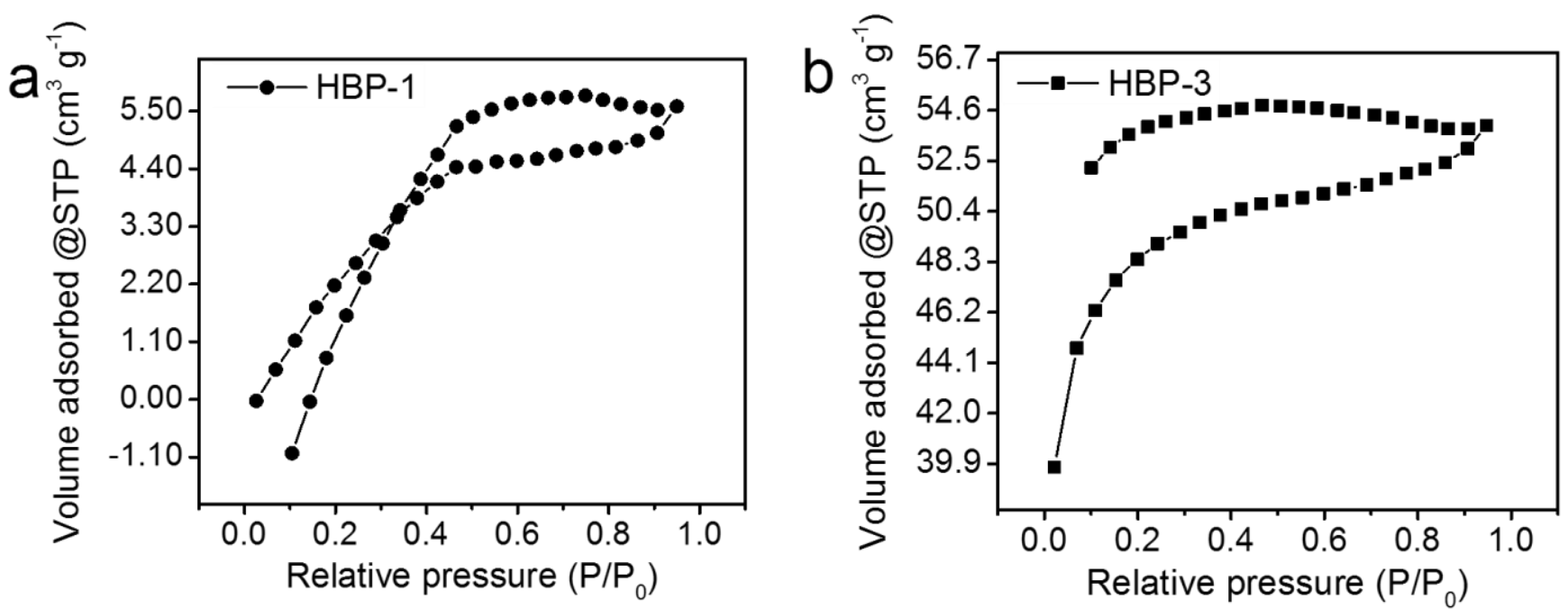

Fig. 3. The $\mathrm{N}_{2}$ adsorption/desorption isotherms: (a) HBP-1; (b) HBP-3.

Table 2. Textural properties of monolithic activated carbon from HBP-s

\begin{tabular}{lcccc}
\hline Samples & $\begin{array}{c}\mathrm{S}_{\mathrm{BET}} \\
\left(\mathrm{m}^{2} \mathrm{~g}^{-1}\right)\end{array}$ & $\begin{array}{c}\mathrm{S}_{\text {MESO }} \\
\left(\mathrm{m}^{2} \mathrm{~g}^{-1}\right)\end{array}$ & $\begin{array}{c}\mathrm{V}_{\text {MESO }} \\
\left(\mathrm{cm}^{3} \mathrm{~g}^{-1}\right)\end{array}$ & $\begin{array}{c}\mathrm{D}_{\text {AVE }} \\
(\mathrm{nm})\end{array}$ \\
\hline HBP-1 & 2.0400 & 5.3589 & 0.0050 & 17.0024 \\
HBP-3 & 154.646 & 0.8950 & 0.0008 & 2.1644 \\
\hline
\end{tabular}

\section{$3.4 X$-ray Diffraction}

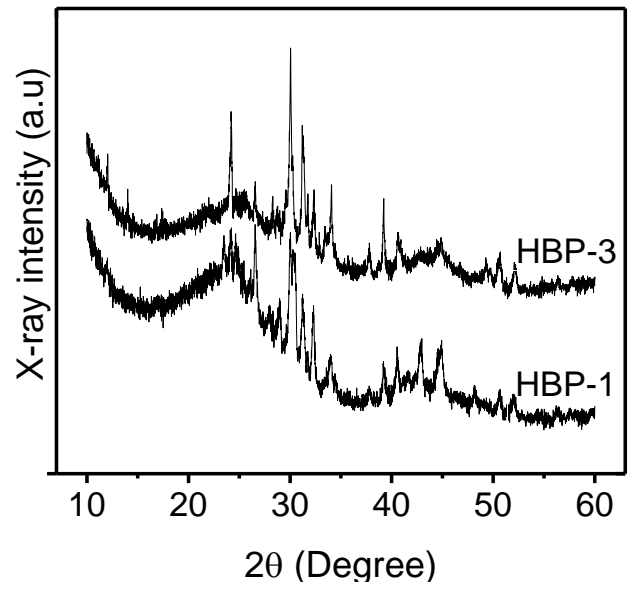

Fig. 4. XRD diffractogram of activated carbon monolith derived HBP-s samples

Fig. 4 shows the X-ray diffractogram of HBP-s crystalline structure, and two broad peaks were obtained at scattering angles $\left(2 \theta\right.$, precisely $24-25^{\circ}$ and $44-46^{\circ}$, reflecting the typical amorphous carbon planes of 002 and 100, respectively. Furthermore, activated carbon from pine bark was used as a reference, and the amorphous content was around $2 \theta$ to $23^{\circ}(002)$ and $44^{\circ}(100)$ [37]. The activated carbon electrode derived bamboo shoot also demonstrated two broad refection peaks at $18-26^{\circ}$ and $42-45^{\circ}$ under different carbonization temperature [38], where the amorphous carbon provides high porosity and increased specific surface area. Meanwhile, the HBP-s sample X-ray diffractogram also showed some sharp peaks indicating impurities. These are associated the presence of some high molecular weight volatiles, including magnesium $\left(2 \theta=36^{\circ}\right.$; MgO; JCPDS card No.89-7746), potassium and calcium $\left(2 \theta=37^{\circ} ; \mathrm{CaO}\right.$; JCPDSNo.82-1690). Specifically, calcium is commonly prone to $\mathrm{CaCO}_{3}$ contamination, being one of the by-product in bamboo pyrolysis [18].

Table 3. XRD parameter of activated carbon monolith derived HBP-s

\begin{tabular}{lccccc}
\hline Samples & $\mathrm{d}_{002}(\AA)$ & $\mathrm{d}_{100}(\AA)$ & $\mathrm{L}_{\mathrm{c}}(\AA)$ & $\mathrm{La}_{\mathrm{a}}(\AA)$ & $\mathrm{Lc} / \mathrm{La}$ \\
\hline HBP-1 & 3.69 & 2.03 & 7.79 & 2.15 & 0.36 \\
HBP-3 & 3.56 & 1.97 & 7.19 & 5.44 & 1.32 \\
\hline
\end{tabular}

Table 3 showed the XRD parameters, including interlayer spacing $\left(d_{002}\right.$ and $\left.d_{100}\right)$ and micro crystallites dimension ( $L_{c}$ for average crystallite sizes and $L_{a}$ for average graphene sheet) characterized by turbostratic crystallite structure. Furthermore, the interlayer spacing $\left(d_{002}\right)$ was calculated using equation 1 , where $3.56 \AA$ and $3.69 \AA$ were obtained for HBP-1 and HBP2 , respectively, indicating the high disorder of carbon atom with amorphous structure. For examples, activated carbon biomass derived from sago waste performed a $d_{002}$ between 3.59 - $3.60 \AA$ [39]. Also, the current investigation shows an inverse relationship between increased $\mathrm{KOH}$ concentration and average crystallites size, characterized by the decline from 7.79 to $7.19 \AA$. This phenomenon was due to the rearrangement of carbon atom during chemical activation at high temperatures of $700{ }^{\circ} \mathrm{C}$. In addition, the increase in the average graphene sheet from 2.15 to $5.44 \AA$, was attributed to the electronegative repulsion of carbon atom [40]. These data confirm the ability for lower crystallite size and higher graphene sheet to provide better specific surface area, corresponding to the Kumar empirical formula $\left(S=2 /\left(\rho L_{c}\right)\right)$, where $S$ denotes the predicted surface area, and $\rho$ is the graphite density [41].

\subsection{Energy Dispersive X-ray}

The energy dispersive X-ray (EDX) was used to evaluate the chemical elements in HBP-s samples, as shown in Table 4. The process of carbonization and chemical activation with $\mathrm{KOH}$ have successfully converted biomass derived bamboo 
into monolithic activated carbon with high carbon content, precisely $\sim 84 \%$ and $\sim 78 \%$ atomic weight for HBP-1 and HBP-2, respectively. Also, the samples showed high oxygen composition of over $10 \%$. In addition, bamboo biomass is known to contain functional groups with a combination of carbon and oxygen, including phenol $(\mathrm{C}-\mathrm{OH})$, quinone $(\mathrm{C}=\mathrm{O})$ or ether (C-O-C), and carboxylic groups $(\mathrm{COOH})$ [2]. However, the oxygen released during the carbonization process was due to low molecular weight and bad thermal stability [15], while carbon percentage decreased alongside the rise in $\mathrm{KOH}$ concentration. These results are associated with the attribution of alkali to the $\mathrm{C}$ and $\mathrm{O}$ bond. In addition, the higher oxygen content in HBP-3 possibly increases wettability and consequently ion diffusion into the electrode deep pores, due to higher amounts of oxygen functional groups [42].

The carbonization and chemical activation process reserve smaller amounts of volatiles, including magnesium, potassium and calcium [14]. Furthermore, the magnesium and calcium components were reduced, while potassium increased at higher $\mathrm{KOH}$ concentrations. These results are attributed to the chemical activation of $\mathrm{KOH}$, which etched the bond of carbon-volatiles and increase $\mathrm{K}_{2} \mathrm{CO}_{3}$-occupied and $\mathrm{K}$-bound [2], due to imperfect removal in the carbon samples [43].

Table 4. Chemical composition analysis from EDX.

\begin{tabular}{lrrrr}
\hline \multirow{2}{*}{ Elements } & \multicolumn{2}{c}{ HBP-1 } & \multicolumn{2}{c}{ HBP-3 } \\
\cline { 2 - 5 } & $\begin{array}{c}\text { Mass } \\
(\%)\end{array}$ & $\begin{array}{c}\text { Atomic } \\
\text { weight (\%) }\end{array}$ & $\begin{array}{c}\text { Mass } \\
(\%)\end{array}$ & $\begin{array}{c}\text { Atomic } \\
\text { weight (\%) }\end{array}$ \\
\hline Carbon & 76.66 & 84.27 & 68.61 & 78.52 \\
Oxygen & 15.54 & 12.83 & 20.34 & 17.48 \\
Magnesium & 1.35 & 0.73 & 0.56 & 0.31 \\
Potassium & 5.05 & 1.70 & 10.50 & 3.69 \\
Calcium & 1.41 & 0.46 & - & - \\
\hline Total & $100 \%$ & & & \\
\hline
\end{tabular}

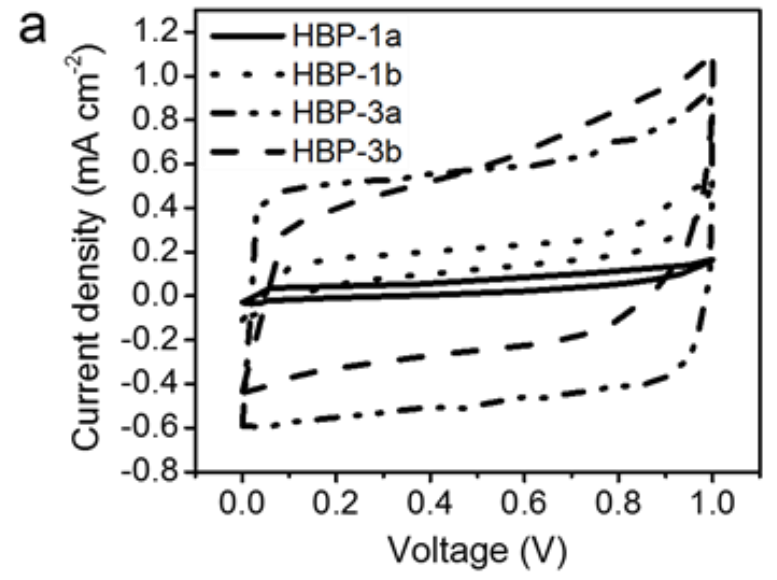

b

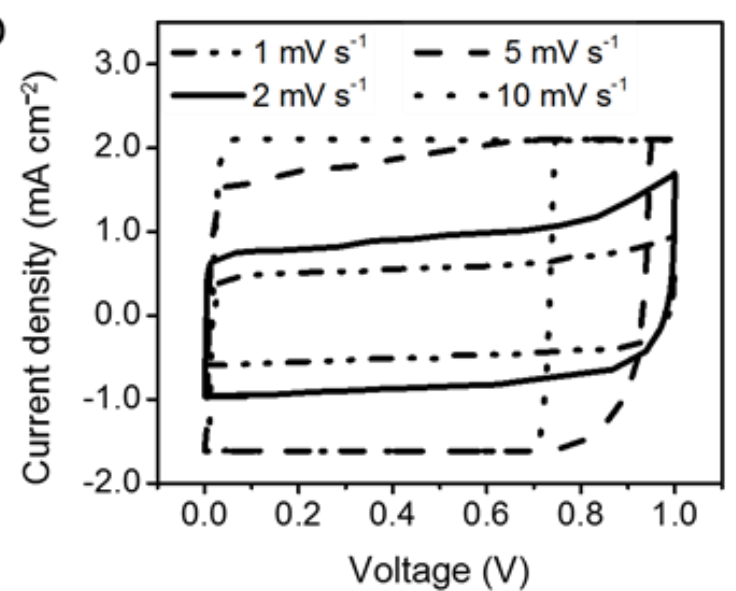

C

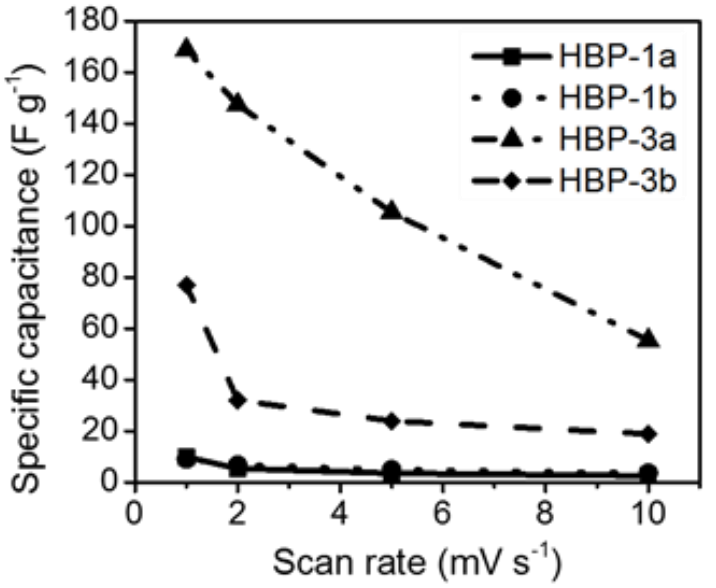

Fig. 5. Electrochemical measurements in a two-electrode system: (a) CV curves from HBP-s samples at a scan rate of $1 \mathrm{mV} \mathrm{s}{ }^{-1}$; (b) CV curve from HBP-3a at different scan rates; (c) the specific capacitance from HBP-s samples at different scan rate.

\subsection{Electrochemical Performance}

The electrochemical performance of HBP-s was evaluated using the cyclic voltammetry $(\mathrm{CV})$ method, where the samples were prepared with two different thickness levels, including $0.2 \mathrm{~mm}$ (a) and $0.3 \mathrm{~mm}$ (b). Figure 5 (a) shows the evaluation process, where two-electrode configurations were used in $1 \mathrm{M} \mathrm{H}_{2} \mathrm{SO}_{4}$ electrolyte, at a scan rate of $1 \mathrm{mV} \mathrm{s}^{-1}$. The results clearly shows the rectangular-like shape structure of the CV curves, typical for EDLC mechanism [29,44]. Furthermore, the specific capacitance $\left(C_{s p}\right)$ was derived following equation 4, characterized by significant improvement from 9.87 to $168.80 \mathrm{~F} \mathrm{~g}^{-1}$ for HBP-1a and HBP$3 \mathrm{a}$, respectively, with thickness of $0.2 \mathrm{~mm}$. Therefore, an 
increase in thickness to $3 \mathrm{~mm}$ also elevated the $C_{s p}$ with varied $\mathrm{KOH}$ concentration at 9.13 and $77.03 \mathrm{~F} \mathrm{~g} \mathrm{~g}^{-1}$ respectively for HBP-1b and HBP-3b. Based on these results, the specific capacitances reported are attributed to morphology structure and the presence of properly developed pores at higher alkali activation [26,32]. Hence, a change in electrode thickness is concluded to not significantly affect the capacitive behavior of $1 \mathrm{M} \mathrm{KOH}$ activation, while the specific capacitance dropped in treatments using the $3 \mathrm{M} \mathrm{KOH}$. In summary, the thinner samples are estimated to provide much better electrochemical performance. This phenomenon is attributed to the lower internal resistance, resulting from the reduced electrode mass, and also the improved specific surface area accessibility, due to the decline in pore block quantity after polishing.

As shown in Fig. 5(b), the CV curves from HBP-3a were steady and rectangular-like at different scan rates, ranging from 1 to $5 \mathrm{mV} \mathrm{s}^{-1}$. This was due to the presence of properly developed pore structure distribution. In addition, threedimensional configurations with large macropores formations also tend to function as ion transport channels, needed for the ion diffusion maintenance at high charge/discharge rates [32]. Also, the flake structure with highly accessible surface enhances electrical conductivity, and consequently increase the number of ion pairs on the surface carbon $[33,34]$.

Table 5. Electrochemical performance from variousactivated carbon-basedbiomassin two-electrode system.

\begin{tabular}{|c|c|c|c|c|c|c|}
\hline Precursor & Activator & $\mathrm{S}_{\mathrm{BET}}\left(\mathrm{m}^{2} \mathrm{~g}^{-1}\right)$ & $C_{s p}\left(\mathrm{~F} \mathrm{~g}^{-1}\right)$ & Electrolyte & 3D structure & Ref \\
\hline Areca catechu husk & $\mathrm{KOH}$ & 757 & 165 & $1 \mathrm{M} \mathrm{H}_{2} \mathrm{SO}_{4}$ & No & [29] \\
\hline Bamboo pieces & $\mathrm{KOH}$ & 2221 & 79 & $3 \mathrm{M} \mathrm{KOH}$ & Yes & {$[18]$} \\
\hline Bamboo fiber & $\mathrm{KOH}$ & 2561 & 47 & $1 \mathrm{M} \mathrm{Na}_{2} \mathrm{SO}_{4}$ & No & {$[25]$} \\
\hline Banana stem & $\mathrm{KOH}$ & 836 & 170 & $1 \mathrm{M} \mathrm{H}_{2} \mathrm{SO}_{4}$ & No & [43] \\
\hline Willow & - & 739 & 93 & $6 \mathrm{M} \mathrm{KOH}$ & Yes & [16] \\
\hline Poplar wood & $\mathrm{KOH}$ & 1612 & 263 & $6 \mathrm{M} \mathrm{KOH}$ & Yes & {$[31]$} \\
\hline Ceder sawdust & $\mathrm{KOH}$ & 1185 & 244 & $1 \mathrm{M} \mathrm{Na}_{2} \mathrm{SO}_{4}$ & Yes & {$[30]$} \\
\hline Wild rice stem & $\mathrm{KOH}$ & 1228 & 81 & $6 \mathrm{M} \mathrm{KOH}$ & No & {$[45]$} \\
\hline Mangosteen peel & $\mathrm{KOH}$ & 1270 & 83 & $6 \mathrm{M} \mathrm{KOH}$ & Yes & [46] \\
\hline Bamboo shoot & $\mathrm{KOH}$ & 3250 & 209 & $6 \mathrm{M} \mathrm{KOH}$ & No & {$[38]$} \\
\hline Bamboo leaves & - & 325 & 162 & $3 \mathrm{M} \mathrm{KOH}$ & No & [47] \\
\hline Hierarchically Bamboo & $\mathrm{KOH}$ & 155 & 169 & Electrolyte & Yes & Current study \\
\hline
\end{tabular}

Fig. 5(c) shows the specific capacitance for HBP-s samples at different scan rate, and the optimized output was observed with HBP-3a at $147.38 \mathrm{~F} \mathrm{~g}^{-1}(87.31 \%)$ and $105.43 \mathrm{~F}$ $\mathrm{g}^{-1}(62.46 \%)$ for scan rate of 2 and $5 \mathrm{mV} \mathrm{s}^{-1}$, respectively. These results confirms the ability for three-dimensional structures with macropores to provide high amount of accessibility for a specific surface area [16]. However, the values respectively remained at $2.56,3.64,55.36$, and $18.92 \mathrm{~F}$ $\mathrm{g}^{-1}$ for HBP-1a, HBP-1b, HBP-3a and HBP-3b, at the highest rate of $10 \mathrm{mV} \mathrm{s}^{-1}$. These capacitances are associated with the diffusion rate of ions into the deeper pore, as an increase in $\mathrm{KOH}$ concentration facilitates to maintain their values, resulting from the high amount of pores developed. Also, the drop is somewhat affiliated with the increase in electrode thickness, due to the ability for pore blocking phenomenon to reduce accessibility to a specific surface area. Furthermore, samples HBP-1a, HBP-1b, HBP-3a and HBP-3b, respectively demonstrated the energy density of $1.37,1.27,23.44,10.69$ $\mathrm{Wh} \mathrm{kg}^{-1}$ for power density of $4.95,4.57,84.46$, and $38.55 \mathrm{~W}$ $\mathrm{kg}^{-1}$. These results are typical for activated carbon biomass electrodes, as bamboo based industrial by-products exhibits values in the term of energy density and power density of 9.5 $\mathrm{Wh} \mathrm{kg}^{-1}$ and $25 \mathrm{~W} \mathrm{~kg}^{-1}$, respectively [17]. Table 5 shows the electrochemical performance from some activated carbonbased biomass reported lasted, where HBP-s displays a high specific capacitance of $168.80 \mathrm{~F} . \mathrm{g}^{-1}$ with energy density of $23.44 \mathrm{Wh} \mathrm{kg}^{-1}$ for power density of $84.46 \mathrm{~W} \mathrm{~kg}^{-1}$.

\section{Conclusion}

Based on the results and discussion, activated carbon in the monolithic form was prepared from hierarchically bamboo stem to improve applicability as a supercapacitor electrode. This was achieved using the stem pellet, through two step carbonizations, assisted with chemical activation. Furthermore, samples activated with $3 \mathrm{M} \mathrm{KOH}$ showed better electrochemical performance than those produced with $1 \mathrm{M}$ $\mathrm{KOH}$ activation in $1 \mathrm{M} \mathrm{H}_{2} \mathrm{SO}_{4}$ electrolyte, characterized by the highest specific capacitance of $168.8 \mathrm{~F} \mathrm{~g}^{-1}$, energy and power density of $23.44 \mathrm{Wh} \mathrm{kg}^{-1}$ and $84.46 \mathrm{~W} \mathrm{~kg} \mathrm{~kg}^{-1}$, respectively, despite the low specific surface area of $154.6 \mathrm{~m}^{2}$ $\mathrm{g}^{-1}$. The activated carbon monolithic obtained a threedimensional pore structure with a flake, resulting in better electrical conductivity, while the high oxygen content causes an increase in wettability, needed for better ion adsorption in the aqueous electrolyte. In addition to specific surface area, electrode architecture plays a more significant role in electrochemical performance, which was better at a thickness of $0.2 \mathrm{~mm}$ than $0.3 \mathrm{~mm}$. Therefore, thinner materials result in lower internal resistance, excellent ion adsorption, and also a promising electrochemical performance. 


\section{Acknowledgements}

The authors are grateful to the DRPM Kemenristek-Dikti for funding in this second year Project of PD with contract number 396/UN.19.5.1.3/PT.01.03/2020 with the title "Highdensity micro-and nano carbon fiber made from biomass based materials for supercapacitor electrodes".

\section{References}

1. S. Koohi-Fayegh, M.A. Rosen, A review of energy storage types, applications and recent developments, J. Energy Storage. 27 (2020) 101047.

2. Y. Wang, Q. Qu, S. Gao, G. Tang, K. Liu, S. He, C. Huang, Biomass derived carbon as binder-free electrode materials for supercapacitors, Carbon 155 (2019) 706-726.

3. K. Fic, A. Platek, J. Piwek, E. Frackowiak, Sustainable materials for electrochemical capacitors, Mater. Today. 21 (2018) 437-454.

4. P. Ratajczak, M.E. Suss, F. Kaasik, F. Béguin, Carbon electrodes for capacitive technologies, Energy Storage Mater. 166 (2018) 126-145.

5. X. Yang, B. Fei, J. Ma, X. Liu, S. Yang, G. Tian, Z. Jiang, Porous nanoplatelets wrapped carbon aerogel by pyrolysis of regenerated bamboo cellulose aerogels as supercapacitor electrodes, Carbohydr. Polym. 180 (2017) 385-392.

6. Z. Xin, W. Fang, L. Zhao, H. Chen, X. He, W. Zhang, N-doped carbon foam constructed by liquid foam with hierarchical porous structure for supercapacitor, J. Porous Mater. 25 (2018) 1521-1529.

7. X. Ma, C. Ding, D. Li, M. Wu, Y. Yu, A facile approach to prepare biomass-derived activated carbon hollow fibers from wood waste as high-performance supercapacitor electrodes, Cellulose. 25 (2018) 4743-4755.

8. J.P. Jyothibasu, D.W. Kuo, R.H. Lee, Flexible and freestanding electrodes based on polypyrrole/carbon nanotube/cellulose composites for supercapacitor application, Cellulose. 26 (2019) 4495-4513.

9. Y. Wu, J. Zhu, L. Huang, A review of three-dimensional graphenebased materials: Synthesis and applications to energy conversion/storage and environment, Carbon 143 (2019) 610-640.

10. E.E. Miller, Y. Hua, F.H. Tezel, Materials for energy storage : Review of electrode materials and methods of increasing capacitance for supercapacitors, J. Energy Storage. 20 (2018) 30-40.

11. M.A. Yahya, Z. Al-qodah, C.W.Z. Ngah, Agricultural bio-waste materials as potential sustainable precursors used for activated carbon production: A review, Renew. Sustain. Energy Rev. 46 (2015) 218-235.

12. M. Inagaki, H. Konno, O. Tanaike, Carbon materials for electrochemical capacitors, J. Power Sources. 195 (2010) 7880-7903.

13. P. Thomas, C.W. Lai, M. Rafie, B. Johan, Recent developments in biomass-derived carbon as a potential sustainable material for supercapacitor-based energy storage and environmental applications, J. Anal. Appl. Pyrolysis. 140 (2019) 54-85.

14. E. Azwar, W. Adibah, W. Mahari, J. Huang, Transformation of biomass into carbon nanofiber for supercapacitor application : A review, Int. J. Hydrogen Energy. 43 (2018) 20811-20821.

15. M. Danish, T. Ahmad, A review on utilization of wood biomass as a sustainable precursor for activated carbon production and application, Renew. Sustain. Energy Rev. 87 (2018) 1-21.

16. C. Jiang, G.A. Yakaboylu, T. Yumak, J.W. Zondlo, M. Edward, J. Wang, Activated carbons prepared by indirect and direct $\mathrm{CO} 2$ activation of lignocellulosic biomass for supercapacitor electrodes, Renew. Energy. 155 (2020) 38-52.
17. W. Tian, Q. Gao, Y. Tan, K. Yang, L. Zhu, C. Yang, H. Zhang, Bioinspired Beehive-like Hierarchical Nanoporous Carbon Derived from Bamboo-based Industrial Byproduct as High Performance Supercapacitor Electrode Material, J. Mater. Chem. A. 3 (2015) 56565664.

18. G. Zhang, Y. Chen, Y. Chen, H. Guo, Activated biomass carbon made from bamboo as electrode material for supercapacitors, Mater. Res. Bull. 102 (2018) 391-398.

19. M. Fujishige, I. Yoshida, Y. Toya, Y. Banba, K. Oshida, Y. Tanaka, P. Dulyaseree, W. Wongwiriyapan, K. Takeuchi, Preparation of activated carbon from Bamboo-cellulose fiber and its use for EDLC electrode material, Biochem. Pharmacol. 5 (2017) 1801-1808.

20. C. Kim, J. Lee, J. Kim, K. Yang, Feasibility of bamboo-based activated carbons for an electrochemical supercapacitor electrode, 23 (2006) 592-594.

21. C. Yang, Y.S. Jang, H.K. Jeong, Bamboo-based activated carbon for supercapacitor applications, Curr. Appl. Phys. 14 (2014) 1616-1620.

22. H. Chen, D. Liu, Z. Shen, B. Bao, S. Zhao, L. Wu, Functional biomass carbons with hierarchical porous structure for supercapacitor electrode materials, Electrochim. Acta. 180 (2015) 241-251.

23. B. Lu, L. Hu, H. Yin, X. Mao, W. Xiao, D. Wang, Preparation and application of capacitive carbon from bamboo shells by one step molten carbonates carbonization, Int. J. Hydrogen Energy. 41 (2016) 1871318720.

24. K. Li, W. Chen, H. Yang, Y. Chen, S. Xia, M. Xia, X. Tu, H. Chen, Mechanism of biomass activation and ammonia modification for nitrogen-doped porous carbon materials, Bioresour. Technol. 280 (2019) 260-268.

25. L. Ji, B. Wang, Y. Yu, N. Wang, J. Zhao, $N, S$ co-doped biomass derived carbon with sheet-like microstructures for supercapacitors, Electrochim. Acta. 331 (2019) 135348.

26. G. Huang, Y. Liu, X. Wu, J. Cai, Activated carbons prepared by the $\mathrm{KOH}$ activation of a hydrochar from garlic peel and their $\mathrm{CO} 2$ adsorption performance, New Carbon Mater. 34 (2019) 247-257.

27. Y. Wen, T. Qin, Z. Wang, X. Jiang, S. Peng, J. Zhang, J. Hou, F. Huang, D. He, G. Cao, Self-supported binder-free carbon fi bers / $\mathrm{MnO} 2$ electrodes derived from disposable bamboo chopsticks for highperformance supercapacitors, J. Alloys Compd. 699 (2017) 126-135.

28. E. Taer, Sugianto, M.A. Sumantre, R. Taslim, Iwantono, D. Dahlan, M. Deraman, Eggs Shell Membrane as Natural Separator for Supercapacitor Applications, Adv. Mater. Res. 896 (2014) 66-69.

29. E. Taer, Apriwandi, R. Handayani, R. Taslim, Awitdrus, A. Amri, Agustino, I. Iwantono, The Synthesis of Bridging Carbon Particles with Carbon Nanotubes from Areca catechu Husk Waste as Supercapacitor Electrodes, Int. J. Electrochem. Sci. 14 (2019) 9436-9448.

30. L. Yang, Y. Feng, M. Cao, J. Yao, Two-step preparation of hierarchical porous carbon from $\mathrm{KOH}$-activated wood sawdust for supercapacitor, Mater. Chem. Phys. 238 (2019) 121956.

31. M. Liu, K. Zhang, M. Si, H. Wang, L. Chai, Three-dimensional carbon nanosheets derived from micro- morphologically regulated biomass for ultrahigh-performance supercapacitors, Carbon 153 (2019) 707-716.

32. X. Wei, J. Wei, Y. Li, H. Zou, Robust hierarchically interconnected porous carbons derived from discarded Rhus typhina fruits for ultrahigh capacitive performance supercapacitors, J. Power Sources. 414 (2019) $13-23$.

33. S. Sankar, A. Talha, A. Ahmed, A.I. Inamdar, H. Im, Y. Bin, Y. Lee, D. Young, S. Lee, Biomass-derived ultrathin mesoporous graphitic carbon nano $f l$ akes as stable electrode material for high-performance supercapacitors, Mater. Des. 169 (2019) 107688.

34. G. Zhang, H. Chen, W. Liu, D. Wang, Y. Wang, Bamboo chopsticks- 
derived porous carbon microtubes/flakes composites for supercapacitor electrodes, Mater. Lett. 185 (2020) 359-362.

35. R.T. Ayinla, J.O. Dennis, H.M. Zaid, Y.K. Sanusi, F. Usman, L.L. Adebayo, A review of technical advances of recent palm bio-waste conversion to activated carbon for energy storage, J. Clean. Prod. 229 (2019) 1427-1442.

36. T. Yumak, G.A. Yakaboylu, O. Oginni, K. Singh, E. Ciftyurek, E.M Sabolsky, Comparison of the electrochemical properties of engineered switchgrass biomass-derived activated carbon-based EDLCs, Colloids Surfaces A. 568 (2020) 124150

37. D. Wang, L. Xu, J. Nai, X. Bai, T. Sun, Morphology-controllable synthesis of nanocarbons and their application in advanced symmetric supercapacitor in ionic liquid electrolyte, Appl. Surf. Sci. 473 (2019) 1014-1023.

38. G. Huang, Y. Wang, T. Zhang, X. Wu, J. Cai, High-performance hierarchical $N$-doped porous carbons from hydrothermally carbonized bamboo shoot shells for symmetric supercapacitors, J. Taiwan Inst. Chem. Eng. 96 (2019) 672-680.

39. E. Taer, A. Afrianda, R. Taslim, A. Agustino, R. Farma, Production of Activated Carbon Electrodes from Sago Waste and its application for an Electrochemical Double-Layer Capacitor, 13 (2018) 10688-10699.

40. J. Serafin, M. Baca, M. Biegun, E. Mijowska, R.J. Kale, Direct conversion of biomass to nanoporous activated biocarbons for high CO2 adsorption and supercapacitor applications, Appl. Surf. Sci. 497 (2019) 143722.

41. K. Kumar, R. Saxena, R. Kothari, D. Suri, K. Kaushik, J. Bohra,
Correlation between adsorption and x-ray diffraction studies on viscose rayon based activated carbon cloth, Carbon 35 (1997) 18421844.

42. X. Song, X. Ma, Y. Li, L. Ding, R. Jiang, Tea waste derived microporous active carbon with enhanced double-layer supercapacitor behaviors, Appl. Surf. Sci. 487 (2019) 189-197.

43. E. Taer, R. Taslim, W.S. Mustika, B. Kurniasih, Agustino, A Afrianda, Apriwandi, Production of an activated carbon from a banana stem and its application as electrode materials for supercapacitors, Int. J. Electrochem. Sci. 13 (2018) 8428-8439.

44. S. Ahmed, M. Rafat, A. Ahmed, Nitrogen doped activated carbon derived from orange peel for supercapacitor application, Adv. Nat. Sci. 9 (2018) 035008.

45. Q. Tian, X. Wang, X. Xu, M. Zhang, L. Wang, X. Zhao, Z. An, H. Yao, J. Gao, A novel porous carbon material made from wild rice stem and its application in supercapacitors, Mater. Chem. Phys. 213 (2018) 267-276.

46. Y. Li, X. Wang, M. Cao, Three-dimensional porous carbon frameworks derived from mangosteen peel waste as promising materials for $\mathrm{CO}_{2}$ capture and supercapacitors, J. CO2 Util. 27 (2018) 204-16.

47. Q. Wang, Y. Zhang, H. Jiang, C. Meng, In-situ grown manganese silicate from biomass-derived heteroatom-doped porous carbon for supercapacitors with high performance, J. Colloid Interface Sci. 534 (2018) 142-155. 